\title{
The laboratory and patient records
}

\author{
W. W. HOLLAND \\ From the Department of Clinical Epidemiology and Social Medicine, St Thomas's Hospital and Medical \\ School, London
}

Investigation of an individual patient consists of three essential processes: first, taking a history; secondly, examining the patient; and thirdly, undertaking a variety of tests such as $x$-ray examinations, biochemical estimations, and so on. Whereas in the past history taking and clinical examination were the most important processes of diagnosis, ancillary investigations are now assuming a far greater importance.

In considering the uses of computers in handling the medical record it is obvious that the ancillary and special investigations lend themselves most readily to computerization, since essentially they consist of numerical or clearly definable information. Even though laboratory information lends itself more easily to computerization, it must be remembered that careful consideration should be given as to what part of the information collected should be stored, and what subsequent value it may have. Thus, in recording information, for example, on haemoglobin measurements in the treatment of a patient with anaemia, it may be wasteful to store in permanent form each haemoglobin measurement that has been made as, otherwise, the computerized medical record may be overwhelmingly filled with laboratory information. In such instances it is only necessary, perhaps, to record the haemoglobin concentration on admission, the lowest haemoglobin concentration, and the haemoglobin concentration on discharge.

The main purposes for which hospital records are used are: first, in medical care; secondly, for administrative and medico-legal purposes; and thirdly, for research which may be prospective or retrospective. Opinions differ as to the value of medical records for any of these purposes. Hospital notes, after all, are mainly designed to provide a record of the patient's condition to be utilized in treatment and management. The main contents of the case record have been summarized as consisting of (1) an identification sheet containing information on date of admission, date of discharge, etc; (2) the initial history and physical examination recorded in narrative form; (3) laboratory data and results of functional tests, $e g$, pulmonary function studies, electrocardiograms, etc; (4) consultation reports containing judgments and therapeutic recommendations in narrative form; (5) operation reports usually in narrative form; (6) therapeutic instructions; (7) follow-up clinical observations; (8) special reports prepared by hospital departments which provide selective services, for example, radiotherapy, physiotherapy, etc; (9) a discharge summary which is a final synthesis of the patient's history, examination, course of treatment, and outcome.

We are here concerned largely with the laboratory and the medical record. Before one can draw any conclusions as to what relationship, if any, laboratory records should have to the patient record, it is important to examine what, in fact, the present record contains.

Holland, de Bono, and Goldman (1964) examined the content of a random sample of the records of patients discharged from St Thomas's Hospital over a 10-week period. They assessed the following points. (1) Whether the diagnosis had been entered in the notes of discharge. (2) Whether the nature of the operation had been entered in the summary on discharge. (3) Whether details of complications incurred by the patient during his stay were entered in the summary. The occurrence of complications was assessed by review of the whole clinical history and temperature and treatment charts. (4) The type and number of special investigations for each patient during inpatient care, and entry of the relevant details in the summary. (5) The time it took for the notes to reach their final destination after discharge of the patient and who handled the notes during this period.

During the investigations 2,303 patients were discharged. Of these 504 were included in the random sample and 480 of their notes were available for examination. The use of laboratory and other investigations is detailed in Table I.

Some investigations were performed frequently, for example, haemoglobin estimations were performed on $62.5 \%$ of all patients. Other frequent investigations were white blood cell counts, bacterio- 
TABLE I

\begin{tabular}{|c|c|c|c|c|}
\hline \multirow[b]{2}{*}{ Investigation } & \multicolumn{3}{|c|}{ ANALYSIS OF LABORATORY AND OTHER INVESTIGATIONS ${ }^{1}$} & \multirow[b]{2}{*}{$\begin{array}{l}\text { No. of } \\
\text { Investigations Noted in } \\
\text { Summary }\end{array}$} \\
\hline & $\begin{array}{l}\text { No. of } \\
\text { Patients }\end{array}$ & $\begin{array}{l}\text { No. of } \\
\text { Investigations }\end{array}$ & $\begin{array}{l}\text { Frequency of } \\
\text { Investigations per Patient } \\
\text { (mean and } S D)\end{array}$ & \\
\hline $\begin{array}{l}\text { ECG } \\
\text { EMG or EEG } \\
\text { Chest radiograph } \\
\text { Ba studies } \\
\text { Radiograph (other) } \\
\text { Haemoglobin } \\
\text { White cell count } \\
\text { ESR } \\
\text { Blood group } \\
\text { Clotting } \\
\text { Blood (other) } \\
\text { Histology } \\
\text { Bacteriology } \\
\text { Blood urea } \\
\text { Electrolytes } \\
\text { Blood sugar } \\
\text { Liver function } \\
\text { Renal function } \\
\text { Chemistry (other) }\end{array}$ & $\begin{array}{r}41(8.5 \%) \\
19(4.0 \%) \\
141(29.4 \%) \\
30(6.3 \%) \\
93(19.4 \%) \\
300(62.5 \%) \\
236(49.2 \%) \\
171(35.6 \%) \\
98(20.4 \%) \\
39(8.1 \%) \\
53(11.0 \%) \\
92(19.2 \%) \\
191(39.8 \%) \\
110(22.9 \%) \\
97(20.2 \%) \\
24(5.0 \%) \\
53(11.0 \%) \\
30(6.3 \%) \\
56(11.7 \%)\end{array}$ & $\begin{array}{r}79 \\
19 \\
216 \\
33 \\
137 \\
549 \\
386 \\
260 \\
99 \\
83 \\
130 \\
98 \\
459 \\
204 \\
263 \\
92 \\
105 \\
80 \\
128\end{array}$ & $\begin{array}{l}1.9 \pm 0.8 \\
1.0 \pm 0.1 \\
1.5 \pm 0.9 \\
1.1 \pm 0.3 \\
1.5 \pm 0.7 \\
1.8 \pm 1.7 \\
1.6 \pm 1.3 \\
1.5 \pm 1.3 \\
1.0 \pm 0.4 \\
2.1 \pm 0.9 \\
2.4 \pm 1.0 \\
1.1 \pm 0.4 \\
2.4 \pm 2.2 \\
1.8 \pm 1.0 \\
2.7 \pm 1.6 \\
3.8 \pm 1.1 \\
2.0 \pm 0.9 \\
2.7 \pm 0.9 \\
2.3 \pm 1.0\end{array}$ & $\begin{array}{r}16(20.2 \%) \\
8(42.1 \%) \\
47(21.7 \%) \\
16(48.4 \%) \\
54(39.4 \%) \\
148(27.2 \%) \\
85(22.4 \%) \\
64(25.1 \%) \\
13(13.2 \%) \\
20(24.0 \%) \\
40(31.8 \%) \\
41(42.2 \%) \\
116(25.4 \%) \\
41(20.1 \%) \\
67(25.5 \%) \\
18(19.5 \%) \\
24(22.9 \%) \\
34(42.5 \%) \\
43(33.6 \%)\end{array}$ \\
\hline Total & & 3,420 & $1 \cdot 83$ & $875(25.6 \%)$ \\
\hline
\end{tabular}

${ }^{1}$ Information reproduced from a table in the Lancet $(1964,1,819)$ by permission of the Editor and Publishers.

logical investigations, ESRs, blood sugar determinations, and renal function tests. The frequency with which these investigations were performed on each patient is also given in the table and it may be seen that where, for example, a clotting test was done in a patient, it was done relatively frequently. Similarly, where blood sugar examinations were performed on a patient they were performed frequently. The EMG or EEG investigations were, however, usually only performed once.

These results give us some idea of the likely amount of information available from laboratory investigations within a normal patient record. The importance to the clinician of these investigations can be judged, perhaps, by examining the frequency with which the results of investigations performed were discussed in the discharge summary.

From the table it is apparent that investigations performed rarely are mentioned frequently; for example, the results of EMG or EEG examinations are considered in the discharge summary in $42 \%$ of patients in which they were performed. Where, however, the investigation is performed frequently, as, for example haemoglobin concentrations, the results are not discussed as frequently as are the rare investigations.

One of the difficulties of introducing laboratory findings into the computerized record is obviously the mechanism by which this is performed. Present thoughts on the uses of computers in laboratories envisage that the laboratory will have its own small computer which will act as a 'baby minder' for the various machines within the laboratory. If one uses such a small laboratory computer the results of laboratory examinations will appear in a printed format. Various types of format have been described (Flynn 1968) and they are entirely adequate. Although this type of computer is perfectly suitable for producing results of analyses and exerting quality control of operations by the daily calculation of means, standard deviations, and, perhaps, of correlation coefficients between different analyses, it is not possible for it to be used for the analysis of the laboratory results in relation to clinical findings.

Correlation with clinical findings would entail transferring the data to a larger machine and entering them in the patient's file. Using an automatic method of transfer requires that there is some form of patient identification present on both the laboratory and clinical record. Hitherto the commonest form of patient identification and the simplest has been the bureau number or hospital number. This usually consists of six or seven digits. Acheson (1967) has clearly described the techniques and drawbacks of various forms of record linkage. Quite obviously, the patient record number is an inadequate means of ensuring proper linkage of both laboratory and patient information. For adequate linkage more than this is required, and $I$ would suggest that it is necessary to enter information, such as the name of the patient, date of birth, and sex. Using these items a match can be made and the information can be useful.We are all, I am sure, familiar with the pile of laboratory records sitting in the medical records department which finds no home.

Up to now I have dealt merely with some mech- 
anical aspects of the need to link the laboratory to the remainder of the patient record. Using a computer with such information can, however, offer exciting possibilities in the analysis of information obtained. Certainly, the presence of the computer may enable one to perform sufficient sophisticated analyses to improve the methods and techniques of using laboratory results in diagnosis.

The first stage is, of course, attempting to discriminate between 'normal' and 'abnormal' findings. In a study that we are doing on the value of multiphasic screening we are collecting the answers of a random sample of patients on a general practitioner's list to about 50 questions. In addition we are doing a number of tests, such as the measurement of ventilatory function, measurement of blood pressure, and ECG, and we are collecting a sample of blood and estimating on this such information as haemoglobin, PCV, MCHC, blood urea, blood sugar, uric acid, serum cholesterol, and proteinbound iodine. In addition, each individual is clinically examined by his own general practitioner and then will be followed up for a number of years.

Quite obviously, we can do simple analyses of the frequency of abnormal findings in laboratory investigations in relation to abnormal physical findings, but having available a large computer we can relate variation in levels of the various biochemical constituents to variations in answers to individual questions as well as to diagnoses. By this means we may be able to approach a far more precise hypothesis as to the meaning of variation in biochemical constituents in relation to the health of the patient.

I am sure that as large computers become increasingly available such investigations will become morecommon. Perhaps we will find that biochemical and other pathological investigations really do open up new diagnostic possibilities and so be used more in the prevention of disease rather than as at present only in the diagnosis and management of established disease.

\section{SUMMARY}

The content and purpose of a medical record is discussed in relation to laboratory results. The use of laboratory results in patients' discharge notes is examined and related to possible computer requirements.

\section{REFERENCES}

Acheson, E. D. (1967). Medical Record Linkage. Oxford University Press, London.

Flynn, F. V., et al (1968). Data processing in clinical pathology. J. clin. Path. 21, 231.

Holland, W. W., De Bono, E., and Goldman, A. J. (1964). Inpatient Records-an investigation of their content and handling at St Thomas's Hospita!. Lancet, 1, 819. 